\section{The hypoxia-responsive transcription factor EPAS1 is essential for catecholamine homeostasis and protection against heart failure during embryonic development}

\author{
Hui Tian, ${ }^{1}$ Robert E. Hammer, ${ }^{2,3}$ \\ Alvin M. Matsumoto, ${ }^{4}$ David W. Russell, ${ }^{1}$ \\ and Steven L. McKnight ${ }^{2,5}$

\begin{abstract}
${ }^{1}$ Department of Molecular Genetics, ${ }^{2}$ Department of Biochemistry, ${ }^{3}$ Howard Hughes Medical Institute, University of Texas Southwestern Medical Center, Dallas, Texas 75235 USA; ${ }^{4}$ Gerontology Research Education and Clinical Center, Veterans Administration Medical Center and Department of Medicine, University of Washington School of Medicine, Seattle, Washington 98195 USA
\end{abstract}

\begin{abstract}
Mice lacking the hypoxia-inducible transcription factor EPAS1 die at mid-gestation. Despite normal morphological development of the circulatory system, EPAS1-deficient mice display pronounced bradycardia. In addition to the vascular endothelium, EPAS1 is expressed intensively in the organ of Zuckerkandl $(\mathrm{OZ})$, the principle source of catecholamine production in mammalian embryos. EPAS1-deficient embryos contained substantially reduced catecholamine levels. Mid-gestational lethality was rescued by administration of the catecholamine precursor DOPS to pregnant females. We hypothesize that EPAS1 expressed in the OZ senses hypoxia during midgestational development and translates this signal into an altered pattern of gene expression, leading to increases in circulating catecholamine levels and proper cardiac function.
\end{abstract}

Received August 17, 1998; revised version accepted September 11, 1998.

Endothelial PAS domain protein 1 (EPAS1) is a hypoxiainducible transcription factor abundantly expressed in vascular endothelial cells (Ema et al. 1997; Flamme et al. 1997; Tian et al. 1997). The primary amino acid sequence of EPAS1 is similar (48\% identity) to that of hypoxiainducible factor $1 \alpha(\mathrm{HIF} 1 \alpha)$, a transcription factor known to induce erythropoietin gene expression in cultured cells in response to hypoxia (Semenza and Wang 1992; Wang et al. 1995). Both EPAS1 and HIF $1 \alpha$ are members of the bHLH-PAS domain family of transcription factors, which include proteins that assist in the detoxification of xenobiotics (Hankinson 1995; Schmidt and Bradfield 1996), the control of circadian rhythm (Kay and Miller 1995; Antoch et al 1997; King et al. 1997), and the speci-

[Key Words: EPAS1; hypoxia; gene targeting]

${ }^{5}$ Corresponding author.

E-MAIL smckni@biochem.swmed.edu; FAX (214) 648-3346. fication of tissue patterning during embryonic development (Nambu et al. 1991; Isaac and Andrew 1996; Wilk et al. 1996).

Although EPAS1 and HIF1 $\alpha$ share substantial primary amino acid sequence similarity and are essentially indistinguishable in their functional properties studied to date, the two proteins are expressed in very different cell and tissue types. In the umbilical cord, for example, EPAS1 is expressed in endothelial cells that line the walls of blood vessels. In contrast, HIF1 $\alpha$ is expressed in smooth muscle cells that surround blood vessels (Tian et al. 1997). Thus, whereas the two proteins probably utilize similar biochemical mechanisms, they are thought to control markedly different physiological pathways dictated by their discrepant sites of expression. As an example, one of the most important targets of HIF1 $\alpha$ gene activation is the erythropoietin gene in the kidney. Because EPAS1 is not present in the peritubular kidney cells that express erythropoietin (Eckardt et al. 1993; Tian et al. 1997), it plays no direct role in the transcriptional induction of this gene in response to hypoxia. To elucidate physiological roles for EPAS1, we disrupted its encoding gene in mice. Here we show that homozygous, EPAS1-deficient embryos die from circulatory failure during mid-gestational embryonic development. Our results are consistent with a fundamental role for EPAS1 in the control of cardiac output.

Disruption of the murine EPAS1 gene was accomplished by homologous recombination in embryonic stem (ES) cells using a targeting plasmid in which a modified form of Escherichia coli $\beta$-galactosidase ( $\beta$-gal) was substituted for exon 2 of the EPAS1 gene (Fig. 1A). Two homologous recombinant stem cell lines were isolated from a total of 768 transfectants, and one of these successfully passed the disrupted EPAS1 gene through the germline (Fig. 1B,C). The introduced mutation eliminated EPAS1 mRNA, as deduced by Northern blot analysis of RNA prepared from homozygous embryonic day 13.5 (E13.5) animals (Fig. 1D).

Mice heterozygous for the EPAS1 mutation were indistinguishable from their wild-type litter mates over a period of 10 months. However, no liveborn homozygous mutant animals were recovered from heterozygous intercrosses, suggesting that the EPAS1 mutation might cause embryonic lethality. To determine the time of death, embryos were genotyped at various developmental stages (Table 1). At E11.5, homozygous embryos with normal appearance were found at the expected Mendelian ratio $(25 \%)$. Beginning at E12.5, the percentage of homozygous, EPAS1-deficient embryos declined, and by E16.5 no viable embryos with this genotype were observed. Similar results were obtained when the disrupted EPAS1 gene was maintained in a congenic 129 background (data not shown). Surviving EPAS1-deficient embryos between E12.5 and E15.5 were grossly normal with no obvious morphological defects.

EPAS1 is capable of activating the Tie2 gene (Tian et al. 1997), which encodes an endothelial cell specific re- 


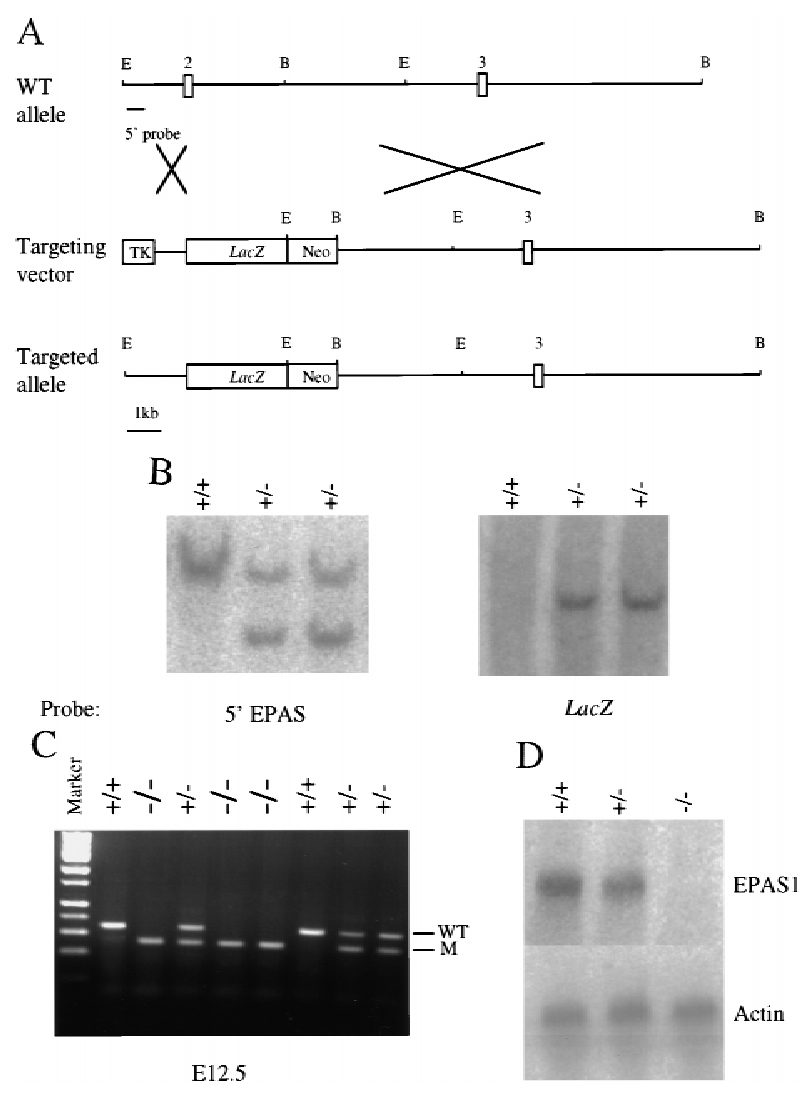

Figure 1. Mutation of the murine EPAS1 gene. (A) Schematic representations of wild-type (WT) EPAS1 allele showing locations of exons 2 and 3 and cleavage sites for EcoRI (E) and $B a m H I$ (B) restriction enzymes, the targeting vector containing a viral thymidine kinase (TK) gene and the E. coli lacZ gene replacing exon 2 of the EPAS1 gene, and the product (targeted allele) of homologous recombination between the wild-type allele and vector. $(B)$ Southern blot analysis of ES cell genomic DNA using a 5' EPAS1 gene probe and a lacZ probe. $(C)$ Inheritance of EPAS1 null allele by embryos of heterozygote crosses judged by PCR analysis of genomic DNA isolated from tails. $(D)$ Blot analysis of total RNA $(20 \mu \mathrm{g})$ isolated from E13.5 embryos using EPAS1 and $\beta$-actin cDNA probes.

ceptor tyrosine kinase required for embryonic angiogenesis (Dumont et al. 1994; Sato et al. 1995). Mice deficient in Tie2 have malformed blood vessels and die between E9.5 and E10.5 (Dumont et al. 1994; Sato et al. 1995). To determine if mutant embryos suffered vascular defects, the expression of EPAS1-driven $\beta$-Gal activity was followed during crucial stages of angiogenesis. As shown in Figure 2A, surrogate EPAS1 expression was detected in the dorsal aorta and the forming intersegmental arteries beginning around E9.0-9.5. Similarly, homozygous embryos stained on E10.5 contained a normally patterned arterial system (Fig. 2B). As shown in Figure 2C, homozygous and heterozygous animals showed indistinguishable patterns of vascular development. These observations indicate that EPAS1 does not play an essential role in either vasculogenesis or angiogenesis.

Previous studies have shown that abnormalities in cardiovascular development, liver hematopoiesis, and for-
Table 1. Genotype offspring from heterozygous matings

\begin{tabular}{lrrrr}
\hline Age & $+/+$ & $+/-$ & $-/-$ & $\begin{array}{r}-/- \\
(\%)\end{array}$ \\
\hline E11.5 & 9 & 18 & 9 & 25 \\
E12.5 & 15 & 25 & 10 & 20 \\
E13.5 & 20 & 40 & 6 & 9 \\
E14.5 & 16 & 29 & 3 & 6 \\
E15.5 & 21 & 41 & 2 & 3 \\
E16.5 & 11 & 25 & 0 & 0 \\
E18.5 & 16 & 36 & 0 & 0 \\
P1 & 72 & 149 & 0 & 0
\end{tabular}

Genotyping was performed by PCR analysis of yolk sac or tail DNA using primers diagnostic for wild-type and mutant alleles. Noon of the day on which a vaginal plug was detected was defined as E0.5 of gestation. (P1) postnatal day 1.

mation of the placenta can lead to mid-gestational lethality (Copp 1995; Uehara et al. 1995). In the dead EPAS1 homozygous embryos, congestion of blood was observed in both the liver and cardiac outflow tracts (Fig. 2D). However, an examination of paraffin-embedded sections derived from live, EPAS1-deficient embryos isolated on E11.5 and E15.5 did not reveal any morphological defects in the heart, liver, or placenta. Taken together, these histological analyses suggested that EPAS1 mutant embryos might die from a physiological rather than developmental cause.

Next, we examined EPAS1 expression in more detail at or near the time of embryonic death. Heterozygous animals were stained with X-gal and sectioned to reveal expressing cells and tissues. In addition to endothelial cells, EPAS1-expression was observed in the sympathoadrenal cell lineage. At E11.5, EPAS1-positive cells were observed in the sympathetic chain (Fig. 3A). One

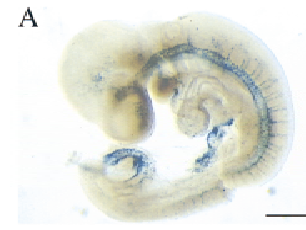

E9.0-9.5,-/-

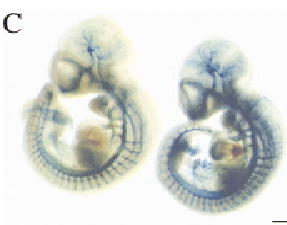

+ - E10.5 -/-

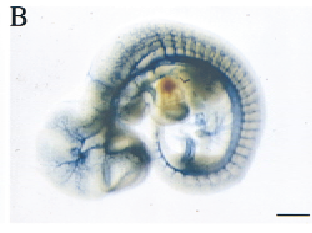

E10.5,-/-

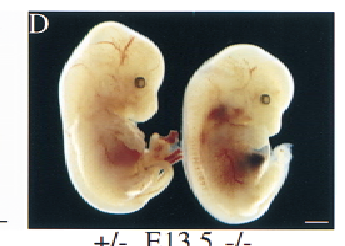

Figure 2. Vasculature and phenotype of EPAS1-deficient mice. $(A-C)$ Surrogate EPAS1 expression in E9.0-9.5 and E10.5 embryos of the indicated EPAS1 genotypes was monitored by whole mount staining for $\beta$-galactosidase enzyme activity. $(D)$ A living embryo heterozygous $(+/-)$ for the EPAS1 null allele and a dead embryo homozygous $(-/-)$ for the mutation were dissected on E13.5 and photographed. Congested blood cells are apparent within the liver of the -/- embryo. Bar, $100 \mu \mathrm{m}(A-D)$. 

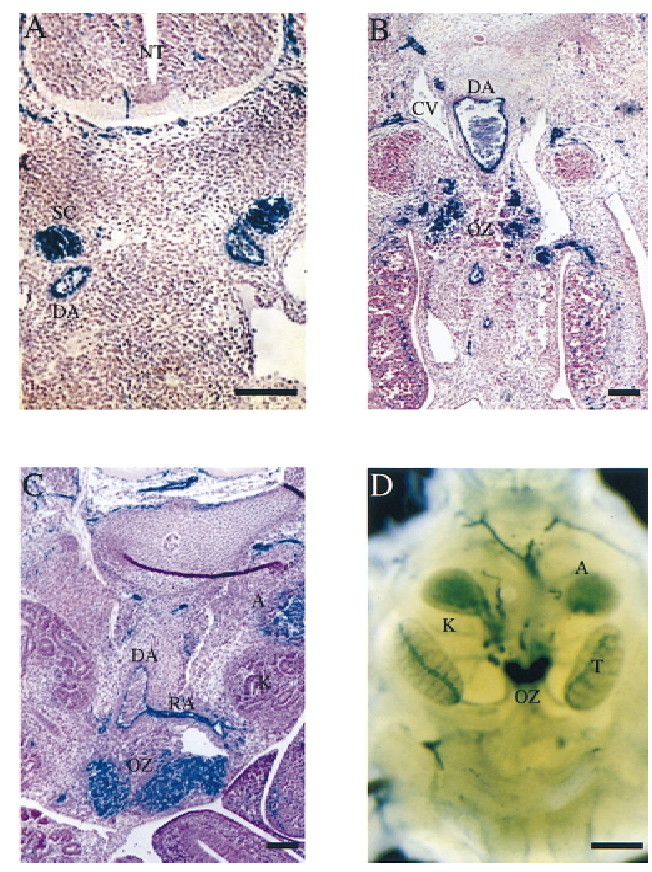

Figure 3. Expression of EPAS1 in the sympathetic chain and OZ. $(A-D)$ EPAS1 expression was monitored in histological sections and whole-mount embryos by $\beta$-gal staining. Sections derived from E11.5 $(A), \mathrm{E} 12.5(B)$, and E13.5 $(C)$ embryos homozygous for a lacZ-tagged EPAS1 allele revealed expression in cells of the sympathetic chain (SC), endothelial cells of the dorsal aorta (DA) and renal artery (RA), and chromaffin cells of the OZ and adrenal gland (A). No expression was detected in cells of the cardinal vein $(\mathrm{CV})$ or neural tube $(\mathrm{NT})$. Bar, $10 \mu \mathrm{m}$. $(D)$ Wholemount staining of a heterozygous embryo on E15.5 revealed intense $\beta$-galactosidase expression in the $\mathrm{OZ}$ and lower levels of expression in the adrenal (A), both of which are located near the kidney $(\mathrm{K})$ and testis $(\mathrm{T})$. Bar, $50 \mu \mathrm{m}$.

day later, EPAS1 expression was down-regulated in these cells but intensively expressed in the forming paraganglia termed the organ of Zuckerkandl (OZ) (Fig. 3B). From E13.5 to E15.5, EPAS1 expression was maintained at a high level in chromaffin cells of the OZ and was also present at lower levels in the adrenal gland (Fig. 3C,D). The temporal expression of EPAS1 in these cells correlated with the time of death of EPAS1-deficient embryos (Table 1).

The OZ represents the major source of fetal catecholamines, especially during early embryogenesis when neither the sympathetic nervous system nor the adrenal medulla is functional (Lagercrantz and Marcus 1992). Catecholamines are required for normal cardiovascular function during embryonic and neonatal development. Mice deficient in genes encoding essential catecholamine biosynthetic enzymes, including tyrosine hydroxylase and dopamine $\beta$-hydroxylase, die at midgestation, presumably because of bradycardia (Kobayashi et al. 1995; Thomas et al. 1995; Zhou et al. 1995).

Catecholamine release in the embryo is known to regulate cardiac output by increasing heart rate (Landsberg and Young 1994). Wild-type E12.5 embryos $(n=33)$ had an average heart rate of $36.0 \pm 6.6$ (mean \pm S.D.) beats per minute, whereas the hearts of EPAS1 deficient embryos $(n=24)$ beat more slowly $(26.9 \pm 8.0)$. The observed difference in heart rate was statistically significant according to both Student's $t$-test $(P<0.001)$ and the Wilcoxon rank sum test $(P<0.001)$. Thus, prior to death, EPAS1-deficient embryos exhibit a measurable slowing of heart rate (bradycardia).

Fetal catecholamine levels were next measured by high pressure liquid chromatography (Thomas et al. 1995). The amount of noradrenaline, the principal catecholamine in the mammalian fetus, was significantly higher $(5.42 \pm 2.15 \mathrm{ng} / \mathrm{mg}$ protein (Phillippe 1983), $n=16, P<0.001$ ) in E12.5 wild-type embryos compared with EPAS1-deficient embryos $(3.21 \pm 0.76 \mathrm{ng} / \mathrm{mg}$ protein, $n=15$ ).

The reduced levels of noradrenaline and the bradycardia observed in EPAS1 deficient-embryos might account for embryonic lethality. To test this hypothesis, we attempted to rescue EPAS1 homozygotes with L-3,4-dihydroxyphenylalanine (L-DOPA), and D,L-threo-3,4-dihydroxyphenylserine (DOPS). L-Dopa can be converted into dopamine and norepinephrine by the consecutive actions of L-aromatic-amino acid decarboxylase and dopamine $\beta$-hydroxylase, respectively, whereas DOPS can be directly converted into norepinephrine by the decarboxylase enzyme. Fresh drinking water containing either LDOPA or DOPS at $1 \mathrm{mg} / \mathrm{ml}$ was administered daily to pregnant females as described (Thomas et al. 1995; Zhou et al. 1995). DOPS prevented mid-gestational death in $\sim 40 \%$ of the mutant embryos, whereas L-DOPA failed to do so (Table 2). The rescued EPAS1-deficient pups were carried to term, at which time they appeared runted, failed to suckle, and died within $24 \mathrm{hr}$ after birth.

The OZ regresses in neonates, and its function as a sensor of hypoxia is largely assumed by the carotid body. This sensory organ is composed of catecholamine-containing type I (glomus) cells, glial-like type II (sustentacular) cells, and afferent chemosensory fibers of the carotid sinus nerve (Peers and Buckler 1995). In response to decreased arterial oxygen, catecholamines are released from the type I cells and stimulate an increase in the sensory discharge from the carotid sinus nerve, which in turn increases respiration and cardiovascular output (Peers and Buckler 1995). As shown, EPAS1 was highly expressed within the carotid body (Fig. 4A). Histological examination at low (Fig. 4B) and high (Fig. 4C) magnification revealed staining in both the endothelial

Table 2. Pharmacological rescue of EPAS1-deficient embryos

\begin{tabular}{lrrrr}
\hline & Total & $+/+$ & $+/-$ & $-/-$ \\
\hline No drug & 221 & 72 & 149 & 0 \\
L-DOPA & 59 & 21 & 38 & 0 \\
DOPS & 118 & 33 & 71 & 14 \\
\hline
\end{tabular}

L-DOPA and DOPS were given in drinking water $(1 \mathrm{mg} / \mathrm{ml})$ to pregnant females from gestation day 8.5 until term. Pups delivered were genotyped by PCR analysis using genomic DNA extracted from tail samples. 

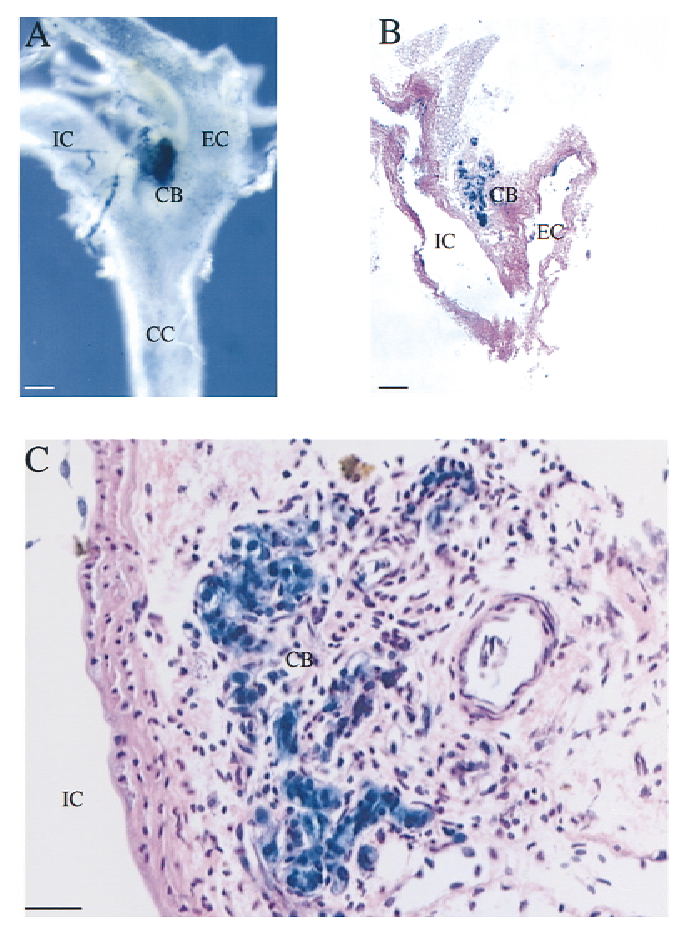

Figure 4. EPAS1 expression in adult carotid body. (A) Wholemount staining of adult (age, 2.5 months) heterozygote showing intense $\beta$-gal expression in the carotid body $(\mathrm{CB})$, which is located at the bifurcation of the common carotid artery $(\mathrm{CC})$ into the internal carotid $(\mathrm{IC})$ and external carotid $(\mathrm{EC})$ arteries. $(B, C)$ Adjacent histological sections revealing expression in the endothelial and type I cells of the carotid body. Bar, $100 \mu \mathrm{m}(B) ; 50$ $\mu \mathrm{m}(C)$.

cells of this highly vascularized organ, and importantly, in the catecholamine containing, cytoplasm-rich type I cells.

The observations presented in this report reveal an essential role for EPAS1 in catecholamine homeostasis in the mammalian embryo. Deficiency of this transcription factor leads to bradycardia, marked reduction in norepinephrine, and mid-gestational fetal death. EPAS1 is expressed at high levels in the chromaffin cells of the OZ, an organ thought to release norepinephrine into the fetal circulation in response to hypoxia (Lagercrantz and Marcus 1992). We hypothesize that EPAS1 expression in the $\mathrm{OZ}$ is hypoxia inducible and, at a mid-gestational point of development, acts as a sensor of hypoxia in the embryo. In response to this signal, EPAS1 induces the expression of genes required for either the synthesis or release of catecholamines. When EPAS1 is absent, catecholamine homeostasis is disrupted, leading to progressive bradycardia and fetal death. In the adult, EPAS1 may have a similar role as a sensor of hypoxia and an effector of catecholamine action in the type I cells of the carotid body.

What are the target genes through which EPAS1 mediates its effects on catecholamine homeostasis? If EPAS1 regulates the synthesis of this class of neurotransmitters, then an attractive candidate gene for EPAS1mediated induction in the $\mathrm{OZ}$ and carotid body is the tyrosine hydroxylase gene. Previous studies have shown that mice deficient in this enzyme activity die at a midgestational time point indistinguishable from EPAS1-deficient animals (Kobayashi et al. 1995; Zhou et al. 1995). Moreover, the tyrosine hydroxylase gene is known to be induced by hypoxia in the carotid body (Czyzyk-Krzeska et al. 1992; Millhorn et al. 1996). Similarly, the observation that DOPS but not L-DOPA rescues EPAS1-deficient embryos (Table 2), suggests that the dopamine $\beta$-hydroxylase gene may be regulated by this transcription factor.

An equally strong argument can be made for EPAS1 regulation of genes involved in catecholamine release. We have noted that all homozygous EPAS1-deficient embryos harbored by heterozygous females die before E16.5 despite having only a $40 \%$ reduction in total norepinephrine levels. In contrast, some homozygous dopamine $\beta$-hydroxylase-deficient embryos borne by heterozygous females survive to term in the face of a $>95 \%$ reduction in norepinephrine levels (Thomas et al. 1995). Complete lethality in the latter animals is only observed in homozygous embryos harbored by homozygous deficient mothers. These results suggest that embryonic lethality in the EPAS1-deficient mice is not directly correlated with a catecholamine biosynthetic defect but, rather, a downstream event in hormone action such as release in response to hypoxia or subsequent uptake at the synapse (Jones et al. 1998).

Regardless of what target genes are regulated by EPAS1 in the catecholamine-secreting cells of the OZ and carotid body, the observations presented in this report document an integral role for EPAS1 in catecholamine homeostasis. If the interpretations made here are correct, then EPAS1 may represent an appealing target for the discovery of drugs that regulate catecholamine homeostasis and the cardiovascular system.

\section{Materials and methods}

\section{Disruption of EPAS1 gene}

A 180-bp mouse EPAS1 DNA probe encoding the bHLH exon was used to isolate BAC clones from a 129/SvJ mouse genomic library (Genome System, Inc.). The genomic structure in the vicinity of the bHLH exon was determined using a combination of restriction enzyme digestion, Southern blotting and long-range PCR. A 1.2-kb PCR fragment containing the EPAS1 genomic sequence 5 ' to the bHLH exon and the first 13 nucleotides of this exon was fused in-frame with a modified bacterial lacZ containing a nuclear localization signal. The resulting $4.5-\mathrm{kb}$ DNA fragment was subcloned into a XhoI site of a targeting vector (pPolII NEO). A 13-kb BamHI fragment containing the DNA sequence 3 ' to the EPAS1 bHLH exon was inserted into a BamHI site in the targeting vector. The vector was linearized with SalI, and $50 \mu \mathrm{g}$ of plasmid DNA was introduced into the ES cell line JH-1 by electroporation. Stable transfectants were selected with G418 and FIAU. After 10 days, colonies were picked, expanded, and screened for homologous recombinants by Southern blotting. Two positive clones were isolated from a total of 768 colonies. Both ES cell clones were injected into C57BL/6 blastocysts. Chimeric male mice obtained were then bred to C57BL/6 and $129 / \mathrm{Sv}$ females to produce heterozygous mice.

\section{Histology}

To detect $\beta$-gal enzyme activity, embryos were fixed in $4 \%$ paraformaldehyde at room temperature for 30-60 min, depending on size. After washing with phosphate-buffered saline (PBS), embryos were stained in $1 \mathrm{mg} / \mathrm{ml}$ 5-bromo-4-chloro-3-indolyl- $\beta$-D-galactoside (X-gal), $5 \mathrm{~mm}$ $\mathrm{K}_{3} \mathrm{Fe}(\mathrm{CN})_{6}, 5 \mathrm{~mm} \mathrm{~K}_{4} \mathrm{Fe}(\mathrm{CN})_{6}, 2 \mathrm{~mm} \mathrm{MgCl}_{2}$, and $100 \mathrm{~mm}$ sodium phos- 
phate $(\mathrm{pH} 7.3)$ at $37^{\circ} \mathrm{C}$ for $2-18 \mathrm{hr}$. Stained embryos were fixed in $10 \%$ neutral buffered formaldehyde solution at $4^{\circ} \mathrm{C}$ overnight. The embryos were then embedded in paraffin and sectioned at $6 \mu \mathrm{m}$. Sections were mounted on glass slides and counterstained with hematoxylin and eosin.

For routine histology, whole embryos or placentae from each genotype were fixed in $10 \%$ neutral buffered formaldehyde solution. Tissues were dehydrated through graded ethanol solutions and embedded in paraffin. Serial sections were cut at $6 \mu \mathrm{m}$ and counterstained with hematoxylin and eosin.

\section{Physiology and pharmacology}

To determine heart rate, E12.5 embryos with placenta attached were isolated from timed pregnant females. Heart rate (no. of contractions per minute) was then counted in solution at $24^{\circ} \mathrm{C}$.

Catecholamine rescue experiments were performed with L-DOPA or DOPS dissolved at a concentration of $1 \mathrm{mg} / \mathrm{ml}$ in water containing 2 $\mathrm{mg} / \mathrm{ml}$ ascorbic acid. Solutions were placed in water bottles attached to individual cages and changed daily. Newborn pups were genotyped by PCR analysis to generate the data of Table 2 .

To measure whole embryo catecholamine levels, fetuses were dissected on E12.5, snap frozen, and stored at $-70^{\circ} \mathrm{C}$. Tissues were homog enized on ice in $200 \mu \mathrm{l}$ of $0.1 \mathrm{~m}$ perchloric acid, $0.01 \%$ cysteine, and 5 $\mu \mathrm{g} /$ liter of 3,4-dihydroxybenzylamine (as internal standard), centrifuged at $4^{\circ} \mathrm{C}$ for $10 \mathrm{~min}(19,000 \mathrm{~g})$, and the resulting supernatant extracted with alumina (Thomas et al. 1995). Catecholamines were eluted from alumina with $0.1 \mathrm{M}$ perchloric acid, $0.01 \%$ cysteine, and quantitated by high pressure liquid chromatography (Thomas et al. 1995).

\section{Acknowledgments}

We thank Yi Xu for excellent technical assistance, Jim Richardson for histological advice, and Joe Goldstein and Elliott Ross for critical reading of the manuscript. This work was supported by grants from National Institutes of Health (DK47657 to D.W.R., DK52031 to S.L.McK.), the Chilton Foundation, and anonymous donations.

The publication costs of this article were defrayed in part by payment of page charges. This article must therefore be hereby marked 'advertisement' in accordance with 18 USC section 1734 solely to indicate this fact.

\section{References}

Antoch, M.P., E.J. Song, A.M. Chang, M.H. Vitaterna, Y. Zhao, L.D. Wilsbacher, A.M. Sangoram, D.P. King, L.H. Pinto, and J.S. Takahashi. 1997. Functional identification of the mouse circadian Clock gene by transgenic BAC rescue. Cell 89: 655-667.

Copp, A.J. 1995. Death before birth: Clues from gene knockouts and mutations. Trends Genet. 11: 87-93.

Czyzyk-Krzeska, M.F., D.A. Bayliss, E.E. Lawson, and D.E. Millhorn 1992. Regulation of tyrosine hydroxylase gene expression in the rat carotid body by hypoxia. J. Neurochem. 58: 1538-1546.

Dumont, D.J., G. Gradwohl, G.H. Fong, M.C. Puri, M. Gertsenstein, A. Auerbach, and M.L. Breitman. 1994. Dominant-negative and targeted null mutations in the endothelial receptor tyrosine kinase, tek, reveal a critical role in vasculogenesis of the embryo. Genes \& Dev. 8: 1897 1909.

Ema, M., S. Taya, N. Yokotani, K. Sogawa, Y. Matsuda, and Y. FujiiKuriyama. 1997. A novel bHLH-PAS factor with close sequence similarity to hypoxia-inducible factor 1alpha regulates the VEGF expression and is potentially involved in lung and vascular development. Proc. Nat1. Acad. Sci. 94: 4273-4278.

Flamme, I., T. Frohlich, M. von Reutern, A. Kappel, A. Damert, and W Risau. 1997. HRF, a putative basic helix-loop-helix-PAS-domain transcription factor is closely related to hypoxia-inducible factor-1 alpha and developmentally expressed in blood vessels. Mech. Dev. 63: 5160 .

Hankinson, O. 1995. The aryl hydrocarbon receptor complex. Annu. Rev. Pharmacol. Toxicol. 35: 307-340.

Isaac, D.D. and D.J. Andrew. 1996. Tubulogenesis in Drosophila: A requirement for the trachealess gene product. Genes \& Dev. 10: 103117.

Jones, S.R., R.R. Gainetdinov, M. Jaber, B. Giros, R.M. Wightman, and M.G. Caron. 1998. Profound neuronal plasticity in response to inac- tivation of the dopamine transporter. Proc. Nat1. Acad. Sci. 95: 40294034.

Kay, S.A. and A.J. Millar. 1995. New models in vogue for circadian clocks. Cell 83: 361-364.

King, D.P., Y. Zhao, A.M. Sangoram, L.D. Wilsbacher, M. Tanaka, M.P. Antoch, T.D. Steeves, M.H. Vitaterna, J.M. Kornhauser, P.L. Lowrey, F.W. Turek, and J.S. Takahashi. 1997. Positional cloning of the mouse circadian clock gene. Cell 89: 641-653.

Kobayashi, K., S. Morita, H. Sawada, T. Mizuguchi, K. Yamada, I. Nagatsu, T. Hata, Y. Watanabe, K. Fujita, and T. Nagatsu. 1995. Tar geted disruption of the tyrosine hydroxylase locus results in severe catecholamine depletion and perinatal lethality in mice. J. Biol. Chem. 270: 27235-27243.

Koury, S.T., M.C. Bondurant, G.L. Semenza, and M.J. Koury. 1993. The use of in situ hybridization to study erythropoietin gene expression in murine kidney and liver. Microscop. Res. Tech. 25: 29-39.

Lagercrantz, H. and C. Marcus. 1992. Sympathoadrenal mechanisms during development. In Prenatal and neonatal physiology (ed. R.A. Polin and W.W. Fox), pp. 160-169. W.B. Saunders, Philadelphia, PA.

Landsberg, L. and J.B. Young. 1994. Functional organization of the autonomic nervous system. In Harrison's principles of internal medicine (ed. K.J. Isselbacher et al.), pp. 412-425. McGraw-Hill, New York, NY.

Millhorn, D.E., L. Conforti, D. Beitner-Johnson, W. Zhu, R. Raymond, T. Filisko, S. Kobayashi, M. Peng, and M.B. Genter. 1996. Regulation of ionic conductances and gene expression by hypoxia in an oxygen sensitive cell line. Adv. Exp. Med. Biol. 410: 135-142.

Nambu, J.R., J.O. Lewis, K.A. Wharton, and S.T. Crews. 1991. The Drosophila single-minded gene encodes a helix-loop-helix protein that acts as a master regulator of CNS midline development. Cell 67: 1157-1167.

Peers, C. and K.J. Buckler. 1995. Transduction of chemostimuli by the type I carotid body cell. J. Membrane Biol. 144: 1-9.

Phillippe, M. 1983. Fetal catecholamines. Am. I. Obstet. Gynecol. 146: $840-855$.

Sato, T.N., Y. Tozawa, U. Deutsch, K. Wolburg-Buchholz, Y. Fujiwara, M. Gendron-Maguire, T. Gridley, H. Wolburg, W. Risau, and Y. Qin. 1995. Distinct roles of the receptor tyrosine kinases Tie-1 and Tie-2 in blood vessel formation. Nature 376: 70-74.

Schmidt, J.V. and C.A. Bradfield. 1996. Ah receptor signaling pathways. Annu. Rev. Cell. Dev. Biol. 12: 55-89.

Semenza, G.L. and G.L. Wang. 1992. A nuclear factor induced by hypoxia via de novo protein synthesis binds to the human erythropoietin gene enhancer at a site required for transcriptional activation. Mol. Cell. Biol. 12: 5447-5454.

Thomas, S.A., A.M. Matsumoto, and R.D. Palmiter. 1995. Noradrenaline is essential for mouse fetal development. Nature 374: 643-646.

Tian, H., S.L. McKnight, and D.W. Russell. 1997. Endothelial PAS domain protein 1 (EPAS1), a transcription factor selectively expressed in endothelial cells. Genes \& Dev. 11: 72-82.

Uehara, Y., O. Minowa, C. Mori, K. Shiota, J. Kuno, T. Noda, and N. Kitamura. 1995. Placental defect and embryonic lethality in mice lacking hepatocyte growth factor/scatter factor. Nature 373: 702-705

Wang, G.L., B.H. Jiang, E.A. Rue, and G.L. Semenza. 1995. Hypoxiainducible factor 1 is a basic-helix-loop-helix-PAS heterodimer regulated by cellular 02 tension. Proc. Nat1. Acad. Sci. 92: 5510-5514.

Wilk, R., I. Weizman, and B.Z. Shilo. 1996. Trachealess encodes a bHLHPAS protein that is an inducer of tracheal cell fates in Drosophila. Genes \& Dev. 10: 93-102.

Zhou, Q.Y., C.J. Quaife, and R.D. Palmiter. 1995. Targeted disruption of the tyrosine hydroxylase gene reveals that catecholamines are required for mouse fetal developent. Nature 374: 640-643. 


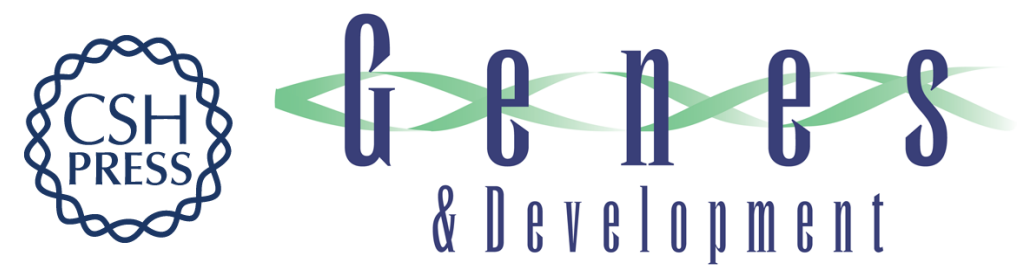

\section{The hypoxia-responsive transcription factor EPAS1 is essential for catecholamine homeostasis and protection against heart failure during embryonic development}

Hui Tian, Robert E. Hammer, Alvin M. Matsumoto, et al.

Genes Dev. 1998, 12:

Access the most recent version at doi:10.1101/gad.12.21.3320

\section{References This article cites 25 articles, 9 of which can be accessed free at: http://genesdev.cshlp.org/content/12/21/3320.full.html\#ref-list-1}

License Email Alerting
Service $\begin{aligned} & \text { Receive free email alerts when new articles cite this article - sign up in the box at the top } \\ & \text { right corner of the article or click here. }\end{aligned}$

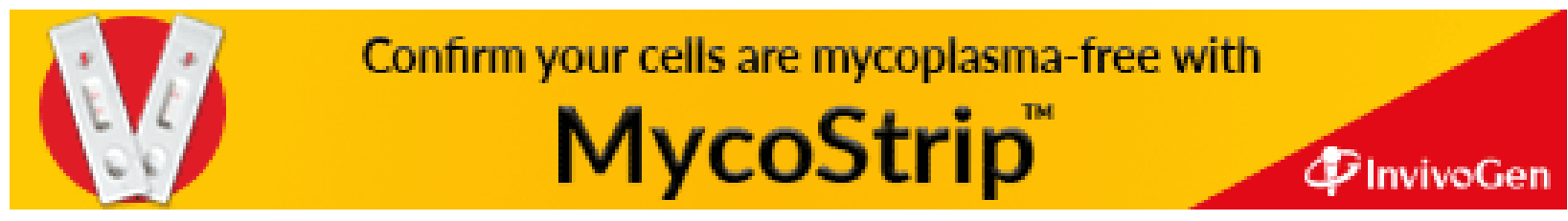

